\title{
Histopathological and Immunohistochemical Findings in Congenital Pouch Colon: A Prospective Study
}

\author{
Hema Udawat ${ }^{a}$ Vandana Nunia $^{d}$ Praveen Mathurc Harsh Prasad Udawat ${ }^{\mathrm{e}}$ \\ Kusum Lata Gaur ${ }^{b}$ Amulya K. Saxena ${ }^{g}$ M. Krishna Mohan ${ }^{f}$ \\ Departments of a Pathology, ${ }^{b}$ Community Medicine and ${ }^{\mathrm{C} P e d i a t r i c ~ S u r g e r y, ~ S . M . S . ~ M e d i c a l ~ C o l l e g e, ~}$ \\ ${ }^{\mathrm{d}}$ Department of Zoology, University of Rajasthan, ${ }^{\mathrm{e} S . D . M . ~ H o s p i t a l, ~ a n d ~}{ }^{\mathrm{f}}$ Birla Institute of Scientific Research, \\ Jaipur, India; ${ }^{9}$ Pediatric Surgery, Imperial College, London, UK
}

\section{Keywords}

Anorectal malformations · Immunohistochemistry ·

Myentric ganglia $\cdot$ Coloplasty actin, myosin, and desmin compared to a normal colon. Conclusions: Histopathological and IHC findings suggest that CPC has distinct defects in the neuromusculature.

(c) 2017 S. Karger AG, Basel

\section{Background}

Congenital pouch colon (CPC) is a rare form of anorectal malformation, in which part of or the entire colon is replaced by a dilated pouch that communicates with a fistula to the genitourinary tract [1].The etiopathogenesis and embryology of CPC are not well understood, but dietary and environmental factors and familial inheritance may contribute to the pathology. The majority of cases of CPC have been reported by various centers in north India. A classification based on anatomical morphology of the pouch categorizes CPC into 5 types [2]. The increase in reports on CPC over the last 4 decades has led to its inclusion under rare anomalies in the "New International Classification of Anorectal Malformations" [3]. The etiopathogenesis of CPC remains speculative. There are enough data on the clinical and surgical aspects of CPC $[1,4-6]$. However, there is a lack of long-term follow-up

\section{KARGER}

(C) 2017 S. Karger AG, Basel

E-Mail karger@karger.com

www.karger.com/pat
Dr Praveen Mathur

24, Shyam Kunj, Laxmi Colony (Opp. Laxmi Mandir Cinema)

Tonk Road

Jaipur 302015, Rajasthan (India)

E-Mail azadanitaashu@gmail.com 
on the functional outcome of CPC surgery and a paucity of literature on the histopathological aspects of CPC [4, 7-13]. To the best of our knowledge, immunohistochemical (IHC) assessment has not yet been attempted and there is no literature available on this. The aim of this study was to compare the histopathology and IHC findings within the CPC spectrum with the normal colon.

\section{Methods}

This was a prospective study carried out in the Department of Pediatric Surgery and Pathology, S.M.S. Medical College, Jaipur, Rajasthan, India. It was carried out between January 2009 and December 2010 after approval from the institutional ethics committee (No. 528/MC/EC/2013, revalidated on Dt 15.02.2013).

In types 3-5 CPC, excision of the pouch and end colostomy is the primary treatment. Hence, the specimens for histopathology were obtained at birth. In types 1 and $2 \mathrm{CPC}$, the primary treatment is pouch colostomy followed by restorative surgery, 3-6 months later, when the child is thriving well. In restorative surgery, coloplasty, i.e., excision of the redundant pouch and tubularization of the residual pouch, is done. So the type 1 and 2 CPC specimens for histopathology were obtained at this stage of the surgery [14].

Sample size was calculated as 12 subjects for each group with an $\alpha$ error of 0.05 and a power of $80 \%$, assuming a $58 \%$ less positive reaction of smooth muscle actin (SMA) staining in CPC cases than in the normal colon. So, 49 cases of neonates suffering from CPC were taken for the study group; 13 cases of idiopathic neonatal colonic perforation requiring excision and end-to-end anastomosis were taken as controls. The diagnosis of CPC was made based on the clinical and surgical findings. Based on the anatomic morphology of the pouch, CPC was classified according to the SaxenaMathur classification [2].

The resected specimens of CPC were fixed in 10\% formalin solution and observed grossly as well as microscopically. For gross examination, the mucosal and serosal surfaces were examined. For microscopic examination, 5 sections were taken from the resected pouch arbitrarily. They were stained with hematoxylin and eosin (H\&E) and Masson trichrome stain. IHC staining was done on 3to 8 - $\mu \mathrm{m}$-thick sections of formalin-fixed paraffin-embedded tissue.

The muscle layers were assessed by immunostaining with commercially available antibodies against SMA, myosin, and desmin (BioGenex Life Sciences Ltd., Hyderabad). Staining on the submucosal vascular wall was taken as a positive internal control. Compared with positive reaction in the submucosal vascular wall, the grading of the positive reaction was recorded as follows: $1=\mathrm{a}$ markedly reduced positive reaction, $2=$ a mildly reduced positive reaction, and $3=$ normal. We adopted the grading system used by Kim et al. [15]. The total thickness of muscle layer (outer and inner circular muscle) was measured by DigiPro Image Analysis v4.0.

The neuron-specific markers S100 and neuron-specific enolase (NSE) were used for the counting of mature ganglionic cells. The number of ganglionic cells $/ \mathrm{mm}^{2}$ was calculated with DigiPro Image Analysis v4.0. The mature ganglionic cells were identified by their large cell body with dispersed chromatin and a prominent nucleolus. If only part of a cell body with the typical cytoplasm was clearly identified, it was also counted [15].

Histopathology of Congenital Pouch Colon

\section{Statistical Analysis}

The significance of difference in proportions of cases and control as per various variables of histopathology and IHC stains was inferred with the $\chi^{2}$ test. The significance of difference in proportions of different types of CPC was also inferred with the $\chi^{2}$ test. Significance of difference in means was inferred with the ANOVA test. For significance, $p<0.05$ was considered significant. The statistical software used for the statistical analysis was Primer v6.0.

\section{Results}

Over a period of 2 years, 347 cases of anorectal malformation were surgically managed; of these, CPC was documented in 49 cases (14.1\%). These 49 cases of CPC were included in the study. The age of the studied neonates ranged from 1 to 4 days, and there were 42 males and 7 females, i.e., the male-to-female ratio was 6:1. Most cases were type $4(n=31$ or $63 \%)$, followed by type $1(n=10)$, type $3(n=4)$, type $2(n=3)$, and type $5(n=1)$.

Gross examination revealed that haustrations and tenia coli were uniformly absent in all types of CPC specimens. Congestion of the serosal surface was observed in only CPC type 4 . On cutting the pouch, the mucosa showed patternless rugosities in all CPC specimens. The normal colon from 13 cases of colonic perforation showed normal tenia coli, haustrations, mucosal rugosities, and serosal surface in comparison to CPC.

Microscopic examination of the control specimens showed normal mucosa and submucosa, and a continuous, undisrupted muscle layer (Fig. 1a). The comparison of histopathological findings in the control colon and CPC is shown in Table 1. Histopathological examination of CPC cases showed abnormalities in the mucosa, submucosa, muscularis propria, and serosa; these findings varied according to the type of CPC (Table 2). It was observed that mucosal changes were seen only in types 1-3 but not in types 4 and 5 . In type 1 CPC, the most common mucosal finding seen was inflammation $(100 \%)$, followed by hemorrhage (70\%), and erosions (60\%) (Fig. 1b). CPC types 2 and 3 showed almost similar findings, along with muscularis mucosae disruption and fibrosis.

Among submucosal changes in CPC, congestion was present in the majority of cases (95.92\%), followed by widening, hemorrhage, inflammation, and the presence of ganglia, lymphoid follicles, fibrosis, and edema (Fig. 1b, c).

Changes in the muscularis propria included the disruption and division of muscle fibers into bands and fibrosis (Table 2). On Masson trichrome staining, fibrosis was more clearly seen, as blue fibers between the muscle fibers

Pathobiology 2017;84:202-209 
Fig. 1. a Normal-appearing mucosa, submucosa, and continuous undisrupted muscularis propria in a normal control colonic specimen. b Ulceration in the mucosa, congestion in the submucosa and serosa, and disorganized muscle bundles in the mucosa in a type 1 CPC specimen. c Type 3 CPC showing congestion in the submucosa and a thickened muscularis propria. a-c Histopathology. H\&E. $\times 50$. d Fibrosis in the muscularis propria, dividing it into various bands, in a specimen from a type 2 CPC. Masson trichrome. $\times 50$. M, mucosa; SM, submucosa; $\mathrm{MP}$, muscularis propria; $\mathrm{S}$, serosa.

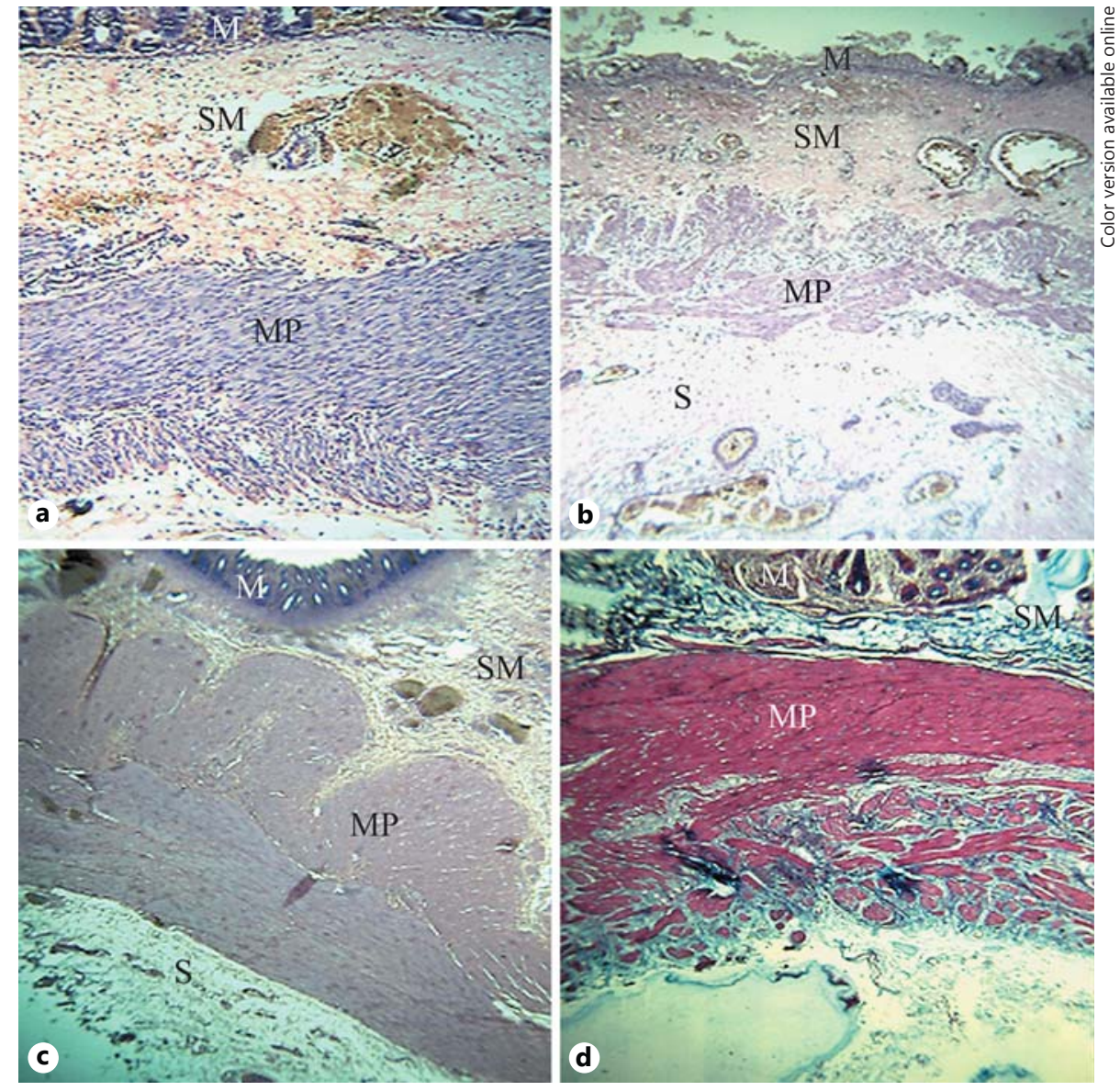

that were stained red (Fig. 1d). Disruption and division into bands due to fibrosis was seen in all types of CPC except for types 4 and type 5 , where the muscularis mucosae were not divided into bands (Fig. 2a). A marked thickness of the muscularis propria and its division into bands was observed significantly more than other changes in the muscularis propria $(p<0.001)$. An additional muscle coat inside of the circular muscle was a predominant finding in type $1(70 \%)$ and type $2(50 \%)$ cases. This muscle coat was separated from the muscularis propria by the ganglionic plexus (Fig. 2b). Mean muscularis propria thickness in types $1-5 \mathrm{CPC}$ was $1.09,2.63,3.2,0.58$, and $1.1 \mu \mathrm{m}$, respectively, whereas it was $0.72 \mu \mathrm{m}$ in controls. It was revealed that muscularis propria thickness was significantly greater $(p<0.05)$ than in controls in every type of CPC except type 4 . Variation in mean muscularis propria thickness was also found to be significant, with the maximum thickness in type 3 and the minimum in type 4 .

Widening and congestion of the serosa were observed in almost all cases (97.96\%) of CPC (Fig. 1b) whereas in- flammation and hemorrhage were found in $20.41 \%$ and $8.16 \%$ cases, respectively.

IHC staining for myosin, desmin, and SMA of control cases revealed equal and homogenous staining of both the muscle layers (Fig. 2c). In type 3 CPC, $50 \%$ of the cases showed markedly reduced, unequal, and patchy positivity in both layers of muscularis propria (Fig. 2d). Staining showed a normal reaction only in $50 \%$ of the type 1 cases and $16 \%$ of the type 4 cases; all type 3 and 5 cases showed a mildly reduced positive reaction. This variation according to CPC type was found significant $(p<0.001)$. There was no difference in the individual patterns of expression of SMA, myosin, and desmin.

On IHC staining for NSE and S100, diffuse cytoplasmic positivity was seen in ganglionic cells in a CPC specimen (Fig. 3). Counting of ganglionic cells per millimeter was done in the myentric ganglion. The control sample had a mean of 2.9 cells $/ \mathrm{mm}^{2}$. In every type of CPC, the ganglion cell number was significantly less $(p<0.05)$ than in the controls. Variation in ganglionic cell number was 
Table 1. Summary of histopathological findings across the spectrum of CPC

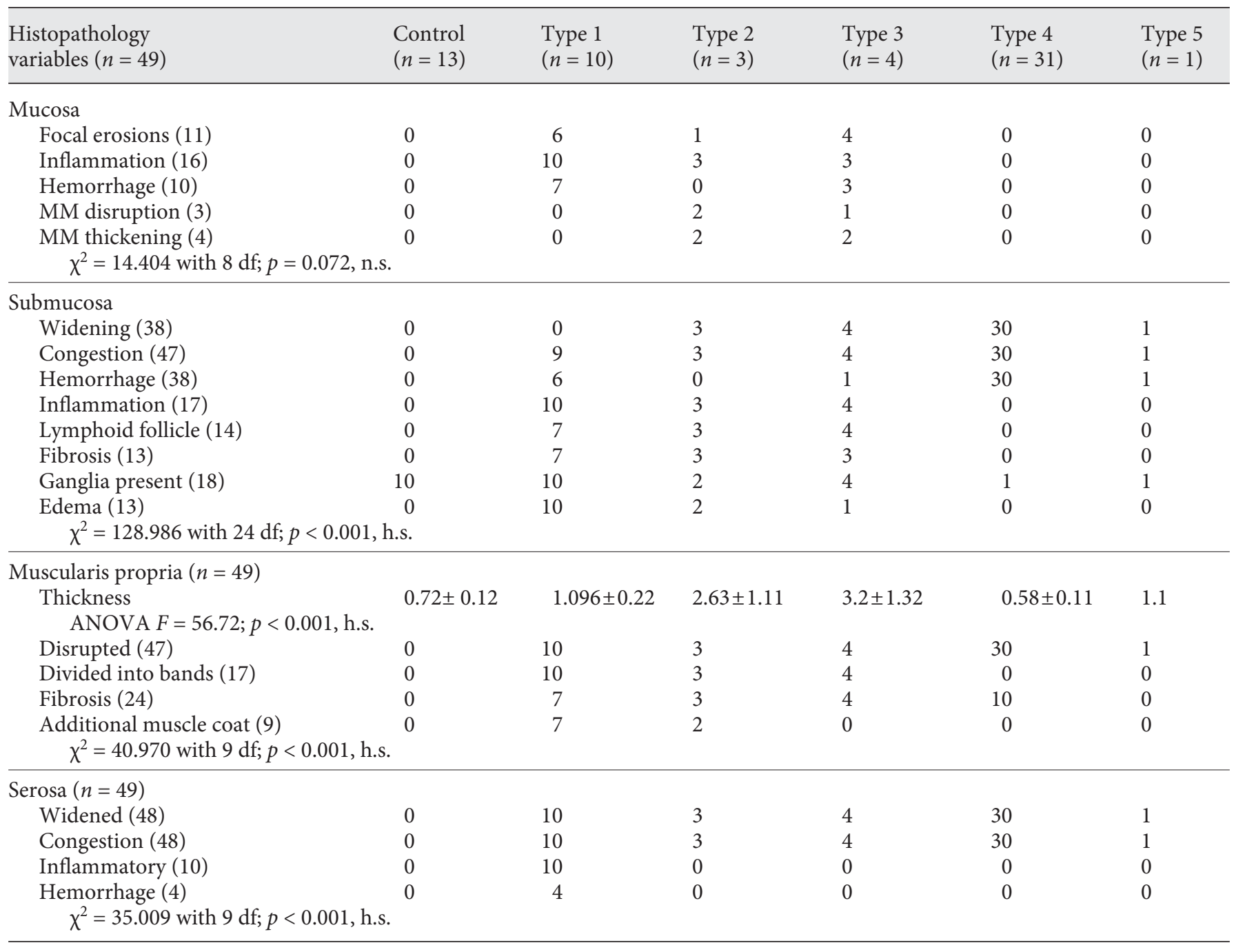

MM, muscularis mucosae; df, degrees of freedom; n.s., not significant; h.s., highly significant.

Table 2. Summary of IHC findings in various types of CPC $(n=49)$

\begin{tabular}{lllllc}
\hline IHC stains and findings & $\begin{array}{l}\text { Control } \\
(n=13)\end{array}$ & $\begin{array}{l}\text { Type 1 } \\
(n=10)\end{array}$ & $\begin{array}{l}\text { Type 2 } \\
(n=3)\end{array}$ & $\begin{array}{l}\text { Type 3 } \\
(n=4)\end{array}$ & $\begin{array}{l}\text { Type 4 } \\
(n=31)\end{array}$ \\
\hline $\begin{array}{l}\text { SMA, myosin, desmin } \\
\quad \text { Markedly reduced positive }(n=2)\end{array}$ & 0 & 0 & 0 & $2(50 \%)$ & 0 \\
$\quad$ Mildly reduced positive $(n=37)$ & 0 & $5(50 \%)$ & $3(100 \%)$ & $2(50 \%)$ & $26(84 \%)$ \\
$\quad$ Normal reaction $(n=10)$ & 13 & $5(50 \%)$ & 0 & 0 & $5(16 \%)$ \\
$\chi^{2}$ test & & 30.513 with 8 df; $p \leq 0.001$, h.s. & 0 \\
\hline
\end{tabular}

df, degrees of freedom; h.s., highly significant.

Histopathology of Congenital Pouch Colon
Pathobiology 2017;84:202-209 DOI: $10.1159 / 000460821$ 
Fig. 2. a Disrupted muscle layer not divided into bands in a type 5 CPC. b Additional muscle coat inside of the muscularis propria in a type $1 \mathrm{CPC}$ specimen. a, b Histopathology. H\&E. $\times 50$. c IHC staining for smooth muscle actin in a control case showing equal and homogenous staining of both muscle layers. $\times 50$. $\mathbf{d}$ IHC staining for smooth muscle actin in type 3 CPC showing unequal and patchy positivity in the muscularis propria. Staining in the submucosal vascular wall was taken as a positive internal control. $\times 50$. M, mucosa; $S M$, submucosa; MP, muscularis propria; $\mathrm{S}$, serosa.

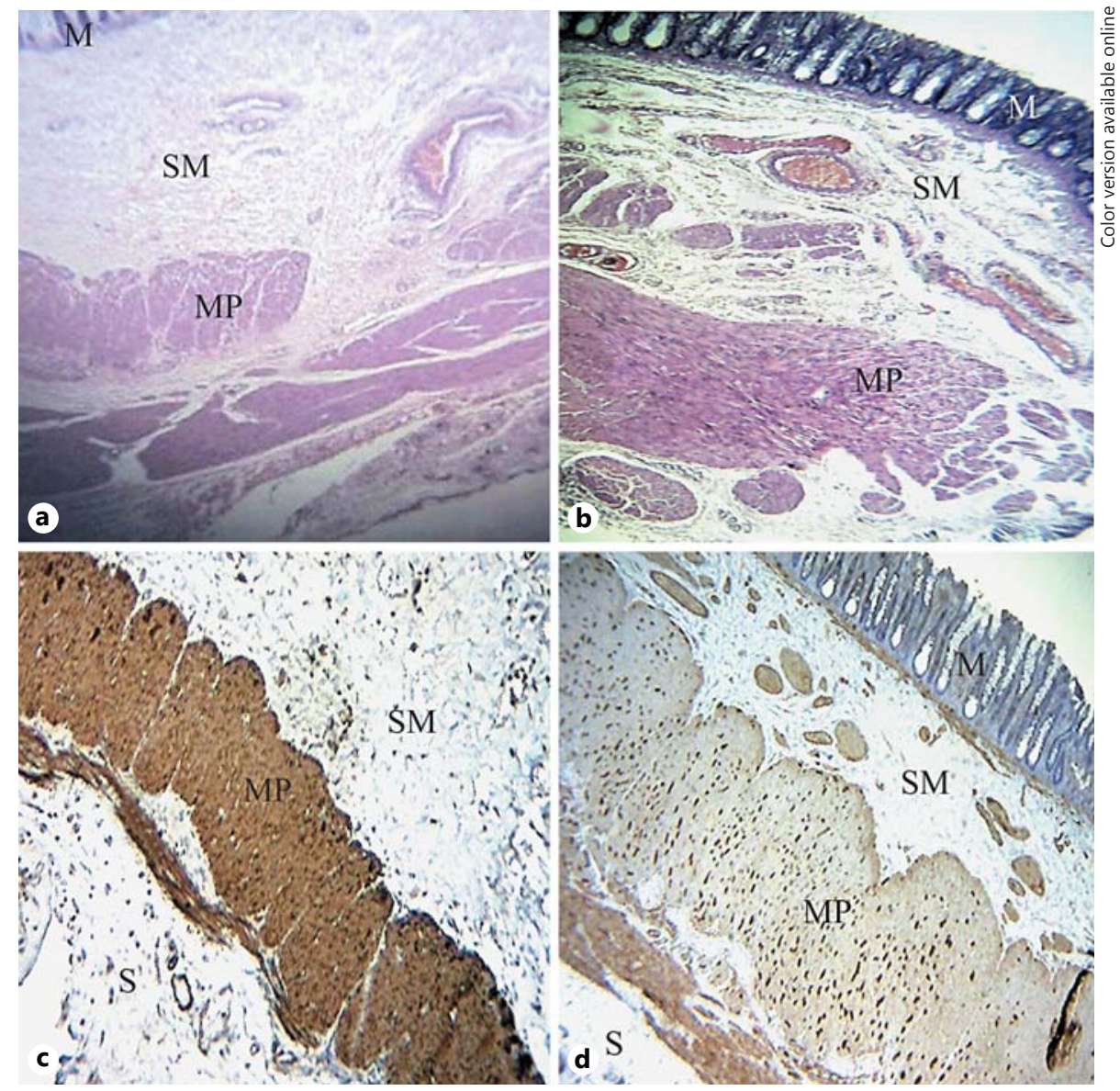

also found to be significant $(p<0.05)$ according to CPC type, with a maximum in type 4 and a minimum in type 1 . Type 1 cases had 0.84 cells $/ \mathrm{mm}^{2}$, type 2 had 0.85 cells/ $\mathrm{mm}^{2}$, type 3 had 0.9 cells $/ \mathrm{mm}^{2}$, type 4 had 1.4 cells $/ \mathrm{mm}^{2}$, and type 5 had 1.0 cells $/ \mathrm{mm}^{2}$. This showed that ganglionic cells were present in all the CPC cases but that their numbers were reduced compared to in the controls.

There was 1 case of type $5 \mathrm{CPC}$ in which the pouch showed a similar histopathology and IHC staining pattern. The findings were similar to CPC type 4.

\section{Discussion}

This study was planned to look into the detailed histopathology of all types of CPC. IHC staining was also done to assess for the contractile proteins of muscle and the number of ganglion cells, in order to evaluate for any defect in neuromuscular structures in the resected CPC specimens. Another aim was to know whether pouch his- tology in type 1 and 2 CPC was abnormal enough to explain the failure of pouch function after coloplasty.

Initial studies observed a normal colonic wall or a reduced number of ganglionic cells in CPC $[4,7,8]$. There have been a few studies in relation to the histopathology of CPC: four on the pouch [9-12] and 1 on the colovesical fistula [13]. Histopathology and IHC were performed on all 5 types of CPC. The overview of previous studies is mentioned in Table 3.

We found marked abnormalities in all the layers of colonic pouch wall. The pouch lacked tenia coli and haustrations. Pattern-less rugosities of mucosa were observed. Inflammation and fibrosis were present in the colon walls. These findings are similar to those of other studies. Prolonged in utero ischemia may be responsible for the inflammatory and fibrotic changes in CPC [9]. The pouch's vascular supply remains compromised by the absence of the inferior mesenteric artery. Depending upon the length of colon with ischemia, there can be different types of pouch [8]. In 1 study, $50 \%$ of the patients had a 


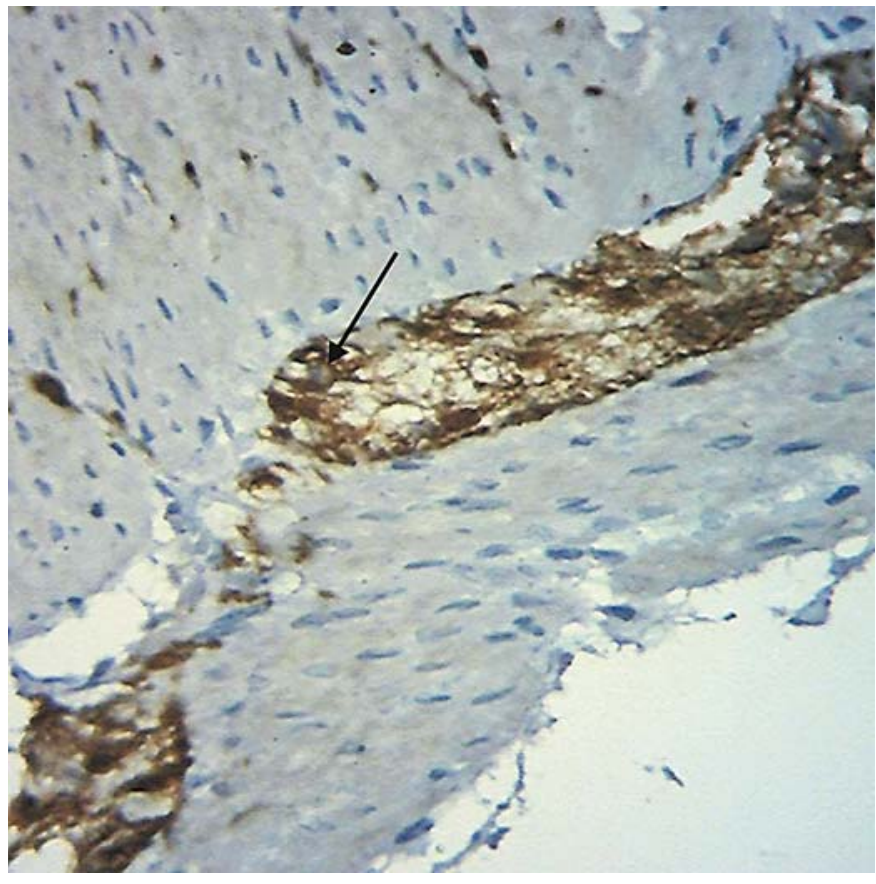

Fig. 3. IHC staining for neuron-specific enolase showing diffuse cytoplasmic positivity in ganglionic cells (arrow) in a CPC specimen. $\times 50$.

normal colonic pouch wall thickness; in our study, the thickness was greater in $16.5 \%$ and smaller in $63.5 \%$ than in the normal controls [9].

The muscularis propria was disrupted and divided into bands due to fibrosis. The presence of fibrous tissue may contribute to dysmotility in cases of CPC. An additional muscle coat was found in types 1 and type 2 CPC only. This focal, fibrotic, and disrupted circular muscle coat was located inside of the circular muscle layer of muscularis propria. This additional muscle layer, along with the disrupted muscularis propria, may cause additional functional obstruction, thereby explaining the poor postoperative results observed in types 1 and 2 CPC. The presence of an additional muscle coat has been previously described in cases of functional intestinal obstruction, intestinal atresia, and some types of CPC [11, 12, 16-18]. In 1 study, it was seen in 5 patients with type 1/ type 2 CPC [11]; in another study, it was seen in only 1 patient [12]. Here, it was present focally, in a discontinuous manner. The orientation of this additional muscle layer was similar to the normal circular muscle, from which it was separated by an additional neural plexus. Broad bands of fibrous tissue separated the muscle bundles of this additional layer. The additional coat may rep-

Histopathology of Congenital Pouch Colon resent misplaced or mispositioned parts of bundles of the inner circular muscle layer $[11,18]$.

The additional muscle coat was not found in types 3-5 in this and in another study [11]. Its presence in these types would not carry any clinical significance, as the pouch has to be removed anyway [14].

Various authors have reported other important observations in the muscle layer. Unique constriction bands were seen in both layers of muscularis propria at intermittent intervals in only 1 study; the authors presumed that these bands, along with the criss-cross arrangement of muscle layers, are responsible for the stasis of fecal matter and meconium in the pouch. These bands were not observed in our study [9]. Other defects in the muscularis propria that have been reported include the lack of differentiation of inner circular and outer longitudinal muscles, arrangement in decussating manner, an incomplete circular muscle layer in $50 \%$ patients, and disorganization of muscle coat in an arborizing manner [19,20]. We did not observe these features. Ectopic tissue, in the form of gastric mucosa and small intestinal mucosa in the pouch, was reported in 1 study [10]. No ectopic tissue was seen in our study.

There was reduced IHC activity for SMA, myosin, and desmin in the muscular propria in the majority of CPC cases. Reduction in these contractile proteins may lead to reduced contractility of the pouch and pouch dysfunction. In 1 study on 12 patients, the muscle strips of the pouch lacked normal spontaneous contractions but retained acetylcholine and histamine-induced contractility [12]. The authors proposed that the CPC pouch is an abnormally functional and developed tissue and should undergo resection. However, the study could not correlate the histology and the absence of spontaneous contractility.

On IHC staining, the number of mature ganglion cells was markedly reduced in all types of CPC in comparison to the controls. The smallest number was seen in type 1 , followed by type 2 , type 3 , type 5 , and type 4 . Only 2 previous studies on the pouch and 1 study on colovesical fistula in CPC noted fewer or absent ganglion cells with a reduction in mature ganglion cells on $\mathrm{H} \& \mathrm{E}$ staining [10, 12]. Another review noted the presence of mature ganglia cells in all cases and giant ganglia in $10 \%$ of cases. The nerve bundles were normal or hypertrophic [19].

In this study, most cases were type 4 CPC. Clinically, type 4 CPC is a less severe form that can be explained by less severe histopathological changes and IHC findings; there were no mucosal changes, no additional muscle coat, and no muscle layer thickening. The significant

Pathobiology 2017;84:202-209 DOI: $10.1159 / 000460821$ 
Table 3. Summary of studies available on histopathological findings in patients with CPC

\begin{tabular}{|c|c|c|c|c|}
\hline $\begin{array}{l}\text { First author [ref.], } \\
\text { year }\end{array}$ & $\begin{array}{l}\text { Patients, } \\
n\end{array}$ & $\begin{array}{l}\text { CPC } \\
\text { type }\end{array}$ & Stains/other tests used & Findings \\
\hline $\begin{array}{l}\text { Our study, } \\
2015\end{array}$ & 49 & $\begin{array}{l}1(n=10) \\
2(n=3) \\
3(n=4) \\
4(n=31) \\
5(n=1)\end{array}$ & $\begin{array}{l}\text { H\&E, Masson trichrome, } \\
\text { IHC stains } \\
\text { (SMA, myosin, desmin, } \\
\text { NSE, S100) }\end{array}$ & $\begin{array}{l}\text { Congestion and hemorrhage in mucosa } \\
\text { (except types } 4 \text { and 5), submucosa, and serosa. } \\
\text { Muscle layer: disrupted, divided into bands } \\
\text { (except types } 4 \text { and 5), fibrosis (except type } 5 \text { ). } \\
\text { Additional muscle coat in types } 1 \text { and } 2 \text { only. } \\
\text { Fewer mature ganglionic cells (a minimum in type } \\
1 \text { and a maximum in type } 4 \text { ). } \\
\text { Reduced and patchy positivity for SMA, myosin, } \\
\text { and desmin. }\end{array}$ \\
\hline $\begin{array}{l}\text { Tyagi [12], } \\
2009\end{array}$ & 12 & & $\begin{array}{l}\text { H\&E, Masson trichrome, } \\
\text { acetylcholine and } \\
\text { histamine contractile } \\
\text { function }\end{array}$ & $\begin{array}{l}\text { Fewer mature ganglion cells. } \\
\text { Muscle layer: fibrosis, disruption, hypertrophy, } \\
\text { atrophy, and constriction bands. } \\
\text { Additional muscle coat }(n=1) \text {. }\end{array}$ \\
\hline $\begin{array}{l}\text { Gangopadhyay [9], } \\
2009\end{array}$ & 24 & $\begin{array}{l}1(n=4) \\
2(n=6) \\
4(n=14)\end{array}$ & H\&E, Masson trichrome & $\begin{array}{l}\text { Mucosal and submucosal inflammation. } \\
\text { Muscle layer: constriction bands, disrupted, } \\
\text { fibrosis, hyper/atrophic. }\end{array}$ \\
\hline $\begin{array}{l}\text { Chatterjee [11], } \\
2009\end{array}$ & 5 & $\begin{array}{l}1(n=2) \\
2(n=3)\end{array}$ & H\&E, Masson trichrome & $\begin{array}{l}\text { Usual large bowel mucosa, fibrosis of submucosa, } \\
\text { focal presence of additional muscle coat }(n=5) \text {. }\end{array}$ \\
\hline $\begin{array}{l}\text { Chadha [13], } \\
2008\end{array}$ & 6 & 1,2 & $\mathrm{H} \& \mathrm{E}$ & $\begin{array}{l}\text { Aganglionosis in muscle layer, submucosal and } \\
\text { subserosal fibrosis, thickness of muscle layer } \\
\text { suggestive of internal sphincter. }\end{array}$ \\
\hline $\begin{array}{l}\text { Agarwal [10], } \\
2005\end{array}$ & 17 & $\begin{array}{l}1(n=8) \\
2(n=4) \\
3(n=1) \\
4(n=4)\end{array}$ & $\mathrm{H} \& \mathrm{E}$ & $\begin{array}{l}\text { Acute and chronic inflammation of mucosa and } \\
\text { submucosa, thinned-out disorganized muscle layer. } \\
\text { Fewer mature ganglion cells, neuronal hypertrophy/ } \\
\text { hyperplasia, ectopic heterotopic tissue. }\end{array}$ \\
\hline
\end{tabular}

changes were: the disruption of the muscle layer by fibrosis, serosal congestion, and a slight reduction in the number of ganglionic cells. In comparison, types 1 and 2 are more severe and can be explained on the basis of the finding of an additional muscle coat, muscle layers divided into bands due to fibrosis, increased muscle layer thickness and a reduced number of ganglionic cells. There was 1 case of type 5 CPC also known as double-pouch colon, in which both the proximal and distal pouches showed similar histopathological and IHC findings. A similar case was reported previously [21].

\section{Conclusions}

Histopathology and IHC of CPC reveal that CPC tissue has striking dissimilarities with the normal colon. The histopathological and IHC findings, which showed disrupted muscle fibers, an additional muscle coat, deranged
SMA, myosin, and desmin, and a reduced number of mature ganglionic cells, suggest that CPC has distinct defects in the neuromusculature.

\section{Acknowledgement}

We are grateful to the Department of Science \& Technology, Government of Rajasthan, Jaipur and ICMR, New Delhi, for financial support and to the Birla Institute of Scientific Research (BISR), Jaipur, and Jaipur Dental College for technical assistance.

\section{Disclosure Statement}

The authors declare that they have no competing interests. 


\section{References}

1 Saxena AK, Mathur P: Congenital pouch colon; in: Puri P (ed): Newborn Surgery, ed 3. London, Hodder Arnold, 2010, pp 582-589.

2 Saxena AK, Mathur P: Classification of congenital pouch colon based on anatomic morphology. Int J Colorectal Dis 2008;23:635639.

3 Holschneider A, Hudson J, Pena A, et al: Preliminary report on the International Conference for the Development of Standards for the Treatment of Anorectal Malformations. J Pediatr Surg 2005;40:1521-1526.

4 Narsimha Rao KL, Yadav K, Mitra SK et al: Congenital short colon with imperforate anus (pouch colon syndrome). Ann Pediatr Surg 1984;1:159-167.

5 Chadha R: Congenital pouch colon associated with anorectal agenesis. Pediatr Surg Int 2004 20:393-401.

6 Gupta DK, Sharma S: Congenital pouch colon, then and now. J Indian Assoc Pediatr Surg 2007;12:5-12.

7 Yadav K, Narsimharao KL: Primary pullthrough as definitive treatment of short colon associated with imperforate anus. Aust NZ J Surg 1983;53:229-230.

8 Wakhlu AK, Wakhlu A, Pandey A, et al: Congenital short colon. World J Surg 1996;20: 107-114.
9 Gangopadhyay AN, Patne SC, Pandey A, Aryya NC, Upadhyaya VD: Congenital pouch colon associated with anorectal malformation - histopathologic evaluation. J Pediatr Surg 2009;44:600-606.

10 Agarwal K, Chadha R, Ahluwalia C, et al: The histopathology of congenital pouch colon associated with anorectal agenesis. Eur J Pediatr Surg 2005;15:102-106.

11 Chatterjee U, Banerjee S, Basu AK, Chatterjee SK: Congenital pouch colon: an unusual histological finding. Pediatr Surg Int 2009;25: 377-380.

12 Tyagi P, Mandal MB, Mandal S, Patne SC, Gangopadhyay AN: Pouch colon associated with anorectal malformations fails to show spontaneous contractions but responds to acetylcholine and histamine in vitro. J Pediatr Surg 2009;44:2156-2162.

13 Chadha R, Agarwal K, Choudhury SR, Debnath PR: The colovesical fistula in congenital pouch colon: a histologic study. J Pediatr Surg 2008;43:2048-2052.

14 Mathur P, Saxena AK, Simlot A: Management of congenital pouch colon based on the Saxena-Mathur classification. J Pediatr Surg 2009; 44:962-966.
15 Kim HK, Cheong H, Kang H, et al: Histopathological evaluation of pediatric intestinal pseudo-obstruction: quantitative morphometric analysis of pathological changes in the enteric nervous system. Korean J Pathol 2010; 44:162-172.

16 Smith VV, Milla PJ: Histopathological phenotypes of enteric muscle diseases causing functional intestinal obstruction in childhood. Histopathology 1997;31:112-122.

17 Masumoto K, Suita S, Taguchi T: The occurrence of unusual smooth muscle bundles expressing alpha smooth muscle actin in human intestinal atresia. J Pediatr Surg 2003;38:161166.

18 Chatterjee SK: Colonic agenesis, pouch colon, rectal ectasia and shared colon; in Surgery of Pediatric Anorectal Malformations. New Delhi, Viva Books, 2005, pp 175-189.

19 Gupta DK, Sharma S: Congenital pouch colon; in Holschneider AM, Hutson JM (eds): Anorectal Malformations in Children: Embryology, Diagnosis, Surgical Treatment, Follow-Up. Berlin, Heidelberg, Springer, 2006, pp 211-221.

20 Luthra M: Congenital short colon. MCh dissertation, All India Institute of Medical Sciences, New Delhi, 1986.

21 Mathur P, Prabhu K, Jindal D: Unusual presentation of pouch colon. J Pediatr Surg 2002; 37:1351-1353.
Histopathology of Congenital Pouch Colon
Pathobiology 2017;84:202-209

DOI: $10.1159 / 000460821$ 